\title{
A Growing Season Water Balance Model Applied to Two Douglas Fir Stands
}

\author{
D. L. Spittlehouse and T. A. Black \\ Department of Soil Science, University of British Columbia, Vancouver, British Columbia \\ Canada V6T $2 A 2$
}

\begin{abstract}
The forest water balance model presented requires only daily solar radiation, maximum and minimum air temperature, and rainfall as the input weather data. Site parameters are root zone depth, soil water retention and drainage characteristics, estimated canopy leaf area index, and the coefficients of the evapotranspiration and rainfall interception submodels. The evapotranspiration submodel calculates the forest evapotranspiration rate as the lesser of energy-limited and soil-limited rates. The former is calculated from the 24-hour net radiation and the latter from the fraction of extractable water in the root zone. Solar radiation and air temperature are used to calculate net radiation. Interception is calculated from the daily rainfall. The root zone is treated as a single layer with drainage calculated as a function of the root zone water content. Water deficits and the matric potential of the root zone are used to indicate tree water stress. The model was tested on two Douglas fir stands of different stand density and leaf area index. The coefficients used in the evapotranspiration submodel were found to be the same for both stands. It was also found that over $20 \%$ of the growing season rainfall was lost through interception.
\end{abstract}

\section{INTRODUCTION}

Practical procedures for estimating the soil water balance of forested watersheds aid in the determination of water yield, the assessment of the growing conditions of the trees, and estimation of forest fire hazard. Such procedures can also be used as a tool in the evaluation of forest management practices [Black and Spittlehouse, 1981]. Since weather information in forested regions is usually limited, the model presented here requires only routinely collected weather data in the calculation of daily evapotranspiration, soil water content of the root zone, and drainage. The main aim of the model is to provide estimates of the water use by the trees and the length of periods of severe water stress experienced by the trees during the growing season. An indication of periods of tree water stress is important, since water stress can severely influence forest growth, e. g., as in the paper by Emmingham and Waring [1977]. The model is tested on two Douglas fir (Pseudotsuga menziesii (Mirb.) Franco) stands of different stand density. The model does not consider conditions of a snow pack or conditions where low temperatures may influence soil water movement or uptake by trees.

\section{BASIS OF THE MODEL}

The model is based on the water balance equation for the root zone, which is treated as a single layer with average soil properties. A multilayered root zone is not used, since soil water extraction functions and information on root distribution and variations of soil hydrologic properties with depth in the profile are not expected to be available for most forest sites. Sharma and Luxmoore [1979] indicate that where the horizontal variability of the hydrologic characteristics is not substantial, average soil properties can be used with minimal error. The average volumetric water content of the root zone $(\boldsymbol{\theta})$ at the end of day $i\left(\bar{\theta}_{i}\right)$ is calculated from

$$
\ddot{\theta}_{i}=\bar{\theta}_{t-1}+\left(P_{i}-E_{i}-D_{i}-R_{i}\right) \Delta t / \zeta
$$

where $\bar{\theta}_{i-1}$ is $\bar{\theta}$ at the end of the previous day, $P_{b} E_{n}, D_{b}$ and $R_{i}$ are the daily rates of precipitation, evapotranspiration, drainage from the root zone and runoff, respectively, expressed as a depth of water per day for day $i, \Delta t$ is a time interval of one day, and $\zeta$ is the root zone depth.

Copyright 1981 by the American Geophysical Union.
The weather data required are the daily (24-hour) net or solar radiation flux density, rainfall, and maximum and minimum air temperature. The site data required are slope, aspect, latitude, root zone depth, soil water retention and drainage characteristics, an estimate of the canopy leaf area index, the coefficients for the evapotranspiration and interception relationships, and the value of $\theta$ at the start of the growing season.

\section{Evapotranspiration}

Forest evapotranspiration models are reviewed by Spittlehouse and Black [1981]. In the present model, transpiration plus soil evaporation $\left(E_{T}\right)$ is calculated separately from the evaporation of intercepted rainfall. The value of $E_{T}$ is the lesser of either weather (net radiant energy) or soil water supply limited rates [McNaughton et al., 1979]. This approach has been chosen because physiologically based models of evapotranspiration, e. g., Tan et al. [1978] or Federer [1979], require a knowledge of the stomatal or canopy resistance characteristics of the vegetation, information that is not readily available for forests.

Energy limited rate. The energy limited rate $\left(E_{\max }\right)$ is calculated using the following relationship proposed by Priestley and Taylor [1972]:

$$
E_{\max }=\alpha E_{\text {eq }}
$$

where $\alpha$ is an experimentally determined coefficient and $E_{e q}$ is the equilibrium evapotranspiration rate. The latter is equal to $(s /(s+\gamma))\left(R_{n}-G-M\right) / L$, where $s, \gamma$, and $L$ are, respectively, the slope of the saturation vapor pressure curve, the psychrometric constant, and the latent heat of vaporization of water each evaluated at the daily average air temperature and $R_{n}, G$, and $M$ are the daily (24-hour) values of, respectively, the net radiation fiux density, the soil heat flux density, and the rate of latent, sensible, and photosynthetic energy storage in the canopy. In calculating $\gamma$ we assume atmospheric pressure to be $100 \mathrm{kPa}$, e. g., $\gamma=0.066 \mathrm{kPa}{ }^{\circ} \mathrm{C}^{-1}$ at $20^{\circ} \mathrm{C}$ [Monteith, 1973]. The daily value of $(G+M)$ is usually less than $5 \%$ of the daily value of $R_{n}$ in coniferous forest [Jarvis et al., 1976] and is neglected in the model.

For a wide range of aerodynamically smooth surfaces, e. g., agricultural crops, $\alpha$ has the value $1.26 \pm 0.2$ [Priestley and Taylor, 1972; Jury and Tanner, 1975]. McNaughton [1976] and 


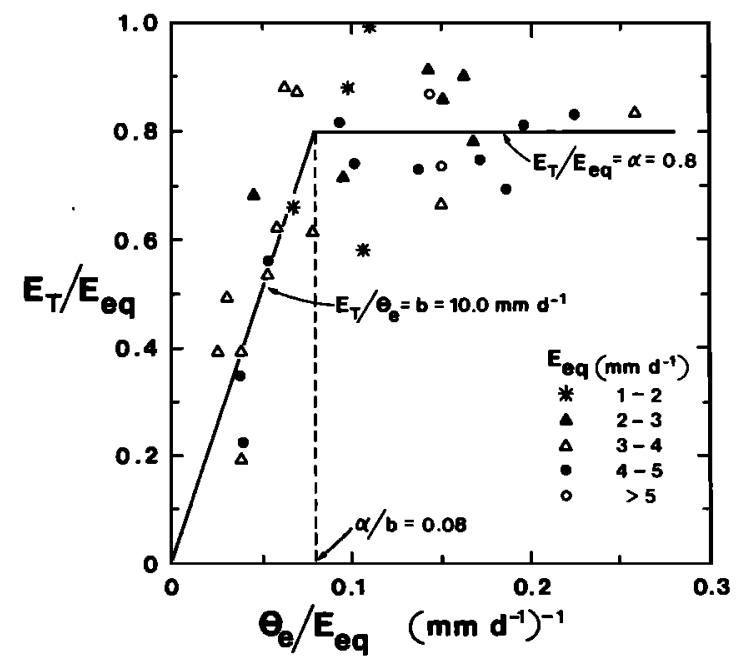

Fig. 1. Daily value of $E_{T} / E_{\mathrm{eq}}$ versus $\theta_{e} / E_{\mathrm{eq}}$ for days with no rain, for a Douglas fir stand (site 2), 29 June to 11 August 1975. Data are from Black [1979]. Symbols are explained in the text.

McNaughton et al. [1979] have suggested that $\alpha>1$ represents mesoscale advective enhancement of evapotranspiration and $\alpha<1$ represents advective suppression or strong surface control through the stomatal resistance of the leaves. In the case of coniferous forests with no intercepted water, values of $\alpha$ are generally between 0.6 and 1.1 though values greater than this have been reported [McNaughton and Black, 1973; Shuttleworth and Calder, 1979; Spittlehouse and Black, 1981]. Some authors have reported values of $\alpha$ calculated for daylight hours only, i. e., $R_{n} \geq 0$. Since 24 -hour net radiation totals are smaller than daylight totals, values of $\alpha$ calculated from daylight totals will be $10-20 \%$ smaller than those calculated on a 24-hour basis.

There are two other general approaches to calculating $E_{\max }$ [Spittlehouse and Black, 1981]. Those involving correlations between daily or weekly mean air temperature and evapotranspiration, e.g., Thornthwaite et al. [1957], Zahner [1967], or Federer and Lash [1978], can be quite inaccurate due to the relatively poor correlation between temperature and net radiation [van Wijk and de Vries, 1954; McNaughton et al., 1979]. Approaches using the Penman equation, e. g., Zahner [1967] or Item, [1978], require more weather data than our approach and tend to overestimate $E_{\max }$ as the region dries.

Soil limited rate. For any value of $\theta$ there appears to be a maximum rate of supply of water $\left(E_{s}\right)$ to the plant that the soil can maintain [Cowan, 1965; McNaughton et al., 1979]. In our model we assume a linear relationship between $E_{s}$ and the fraction of extractable water in the root zone $\left(\theta_{e}\right)$, i.e.,

$$
E_{s}=b \theta_{e}
$$

where $b$ is experimentally determined and $\theta_{e}=\left(\bar{\theta}-\bar{\theta}_{\min }\right) /$ $\left(\bar{\theta}_{\max }-\bar{\theta}_{\min }\right)$. The value of $\bar{\theta}$ is given by $\left(\int_{0}^{5} \theta(z) d z\right) / \zeta$, where $\theta(z)$ is the volumetric water content of the soil as a function of depth $z$. The symbols $\theta_{\max }$ and $\dot{\theta}_{\min }$ are, respectively, the values of $\dot{\theta}$ when drainage is small, i.e. field capacity, and when transpiration virtually ceases [Black, 1979]. The value of $\theta_{e}$ for any day is calculated from $\bar{\theta}$ at the end of the previous day. On days when $\theta_{e}$ may change significantly due to heavy rain or significant drainage, evapotranspiration is energy limited.

The model computes $E_{T}$ as the lesser of $E_{\max }$ and $E_{s} A$ plot of $E_{T}$ versus $\theta_{e}$ produces a set of lines representing (2), parallel to the $\theta_{e}$ axis, which intersect the sloping line representing (3) at a critical value of $\theta_{e}\left(\theta_{e c}\right)$, where $E_{\max }=E_{s}$. Thus there is a unique value of $\theta_{e c}$ for each value of $E_{e q}$. It can be shown that plotting $E_{T} / E_{e q}$ versus $\theta_{e} / E_{e q}$ reduces the above-mentioned plot to two straight lines that intersect at $\theta_{e c} / E_{e q}=\alpha / b[\mathrm{Fed}$ erer, 1979; Spittlehouse, 1981]. This relationship between $E_{T}$ $E_{e q}$, and $\theta_{e}$ is illustrated in Figure 1 using data from Black [1979] for a 23-year-old Douglas fir stand during July and August, 1975. When $\theta_{e} / E_{e q}>\alpha / b, E_{T}=E_{\max }$, and when $\theta_{e} / E_{e q}<$ $\alpha / b, E_{T}=E_{s}$

Evaporation of intercepted rainfall. During and shortly after a rainstorm the evaporation rate of intercepted rain from a fully wet canopy may be greater than $R_{n}$. This is due to the lack of surface control of evaporation and mesoscale advective enhancement [McNaughton and Black, 1973; Rutter, 1975; Stewart, 1977; Shuttleworth and Calder, 1979]. Consequently, values of $\alpha$ much greater than those for dry surfaces are obtained when the foliage is wet. We use the relationship proposed by McNaughton and Black [1973] and Shuttleworth and Calder [1979] for estimating the evapotranspiration rate on rainy days, as follows:

$$
E=E_{\max }+g I
$$

where $I$ is the daily rainfall interception, calculated from the interception model described below, and $g$ is an experimentally determined coefficient. Gash (1978) has shown the theoretical basis of (4). If $E>I$, then all of the intercepted water is assumed to have evaporated and $E_{T}$ is the lesser of $(E-I)$ and $E_{s}$. If $I \geq E$, then $E_{T}=0$ and $(I-E)$ up to the saturated interception capacity $(S)$ of the canopy is left until the next day. The amount of water present at saturation is approximated by a layer of water $0.2 \mathrm{~mm}$ thick over the upper surface of the foliage [Rutter, 1975], i.e., $S=0.2$ LAI (mm), where LAI is the leaf area index of the canopy. This assumes that the storage of rain on the trunks and branches is negligible.

\section{Interception}

Daily interception is calculated using

$$
\begin{array}{cl}
I=f P^{\prime} & P>P_{c} \\
I=P & P \leq P_{c}
\end{array}
$$

where $f, l$, and $\boldsymbol{P}_{c}$ (the maximum daily rainfall that appears to be entirely intercepted) are experimentally determined values [Rutter, 1975]. To account for the different LAI of the two stands considered here, LAI is empiricallly included in (5) by setting $f=p \mathbf{L A I}$, where $p$ is a constant.

\section{Runoff, Infiltration, and Drainage}

Runoff is neglected in the model because the two sites modeled here had surfaces covered by vegetation, slopes of less than $10 \%$, and soils with high infiltration capacities. In freely draining soils of varying textures, the hydraulic gradient is often approximately equal to the gravitational gradient [Black et al., 1969; Harr, 1977]. In this situation, called the unity gradient, drainage can be approximated by the hydraulic conductivity $(k)$ evaluated at the volumetric water content $(\theta)$ of the soil in the lower part of the soil profile [Hillel and van $\mathrm{Ba}$ vel, 1976; Federer, 1979]. From the above, Black et al. [1969] and Clothier et al. [1977] showed that drainage can be expressed as a function of the water content of the whole profile, i. e., a $D(\nexists)$ characteristic. This characteristic, which is used to calculate drainage in our model, can be obtained in the field 
using a soil water balance procedure. Drainage is calculated daily, based on $\theta$ at the beginning of the day, except when drainage could be greater than $3 \mathbf{~ m m ~} d^{-1}$. In this case, rainfall minus interception is divided into six equal amounts and drainage is calculated on a 4-hour basis. In coarse soils with a deep water table, upward flow is small because $k$ is usually very small by the time the hydraulic gradient reverses. Since this is the case at our sites, our model neglects upward flow.

\section{Determining Periods of Tree Water Stress}

As was noted earlier, our major use of the model is in determining the severity and duration of the periods of tree water stress. Tree water stress is a consequence of the inability of trees to meet the atmospheric evaporative demand for water when available soil water is low. Consequently, the model sums the daily water deficit for dry foliage $\left(E_{\max }-E_{T}\right)$ over the growing season. The average root zone matric potential $\left(\bar{\psi}_{m}\right)$ is also used as an indicator of the degree of water stress. Tan et al. [1978] showed that stomatal opening can be substantially reduced in the stands considered here when $\psi_{m}<$ $-0.95 \mathrm{MPa}$. The average root zone matric potential characteristic $\left(\bar{\psi}_{m}(\bar{\theta})\right)$ and $\bar{\theta}$ are used to obtain $\bar{\psi}_{m}$.

\section{Site Description AND DATA Collection}

The model was evaluated on unthinned (site 1) and thinned (site 2) Douglas fir stands planted in 1953, located $26 \mathrm{~km}$ northwest of Courtenay on Vancouver Island [Nnyamah and Black, 1977; Tan et al., 1978; Black, 1979; Spittlehouse, 1981].

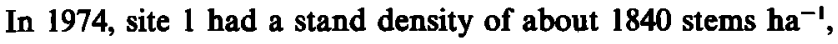
an average tree height of $9 \mathrm{~m}$, a LAI (calculated on a projected area basis) of $7.2 \pm 1$, and negligible understory. Site 2 had a stand density of $820-840$ stems ha ${ }^{-1}$ (originally 1520 stems ha $\mathrm{ha}^{-1}$ in 1974), tree heights of 9 and $12.5 \mathrm{~m}$, and values of tree LAI of $3.6 \pm 0.5$ and $5.0 \pm 0.5$ in 1975 and 1978-1979, respectively. Site 2 also had a salal (Gaultheria shallon (Pursh)) understory with a LAI of $3.0 \pm 0.5$ in all three years. The root zone soil at both sites was a gravelly sandy loam, over sandstone, of depth 0.65 and $0.75 \pm 0.25 \mathrm{~m}$ at sites 1 and 2, respectively. Root density decreased gradually with depth. The sites were about $150 \mathrm{~m}$ above sea level and had slopes of less than $10 \%$ with a NE aspect. They were surrounded for at least $5 \mathrm{~km}$ by a forest of similar age. Topography is generally flat with a few ridges of $20-30 \mathrm{~m}$ relief. The region is in a rain shadow and has warm droughty summers.

The values of $\alpha$ and $b$ were $0.8 \pm 0.07$ and $10 \pm 1 \mathrm{~mm} \mathrm{~d}^{-1}$, respectively, (c.f. Figure 1). They were obtained for site 2 from 29 June to 11 August 1975 with evapotranspiration measured using the Bowen ratio/energy balance method and $\theta$ obtained using a neutron moisture probe and gravimetric sampling [Black, 1979; Spittlehouse and Black, 1980]. Data for the few rainy days, with interception estimated using (5), suggested a value of $0.6 \pm 0.2$ for $g$. Shuttleworth and Calder [1979] used $g=0.93$ for $\alpha=0.72$, while McNaughton and Black [1973] estimated $g=0.17$ for $\alpha=1.05$ for their coniferous forests. The coefficients in the interception model were obtained from site 2 in 1978 using five below-canopy and one above-canopy rain gauges. Stemflow was observed to be small. The values of $p, l$, and $P_{c}$ were $0.08,0.6$, and $0.5 \mathrm{~mm}$ $\mathbf{d}^{-1}$, respectively.

Tensiometer and hygrometer measurements of matric potential $\left(\psi_{m}\right)$ and neutron moisture probe measurements of $\theta$ with depth [Nnyamah and Black, 1977; Spittlehouse, 1981] were used to determine a $\Psi_{m}(\bar{\theta})$ characteristic. Following
Campbell [1974] and Clapp and Hornberger [1978], the data for the unsaturated range were described by $\psi_{m}=\psi_{m r}(\theta)$ $0.3)^{-m}$ and the average characteristic was obtained by averaging the values of $m$ and of $\psi_{m r}$ for each measurement depth. The values of $m$ were $5.2 \pm 0.6$ and $5.9 \pm 0.3$, and those of $\psi_{\mathrm{mr}}$ were $-2.8 \pm 1.2$ and $-0.9 \pm 0.5 \mathrm{kPa}$ at sites 1 and 2 , respectively. The characteristics agreed well with laboratory retention data for site 2. The values of $\theta_{\max }$ and $\theta_{\min }$ were 0.22 and 0.08 , and 0.21 and 0.08 for sites 1 and 2, respectively, which correspond to values of $\psi_{m}$ of approximately $-0.01 \mathrm{MPa}$ and $-2.5 \mathrm{MPa}$, respectively.

A $D(\bar{\theta})$ characteristic was determined for site 2 from the residual term in water balances calculated during September 1978. The water balances used estimates of evapotranspiration from (2), measured $P$ and $I$, and changes in $\theta$ calculated from both daily tensiometer profiles of $\psi_{m}$ and the $\psi_{m}(\bar{\theta})$ characteristic. Tensiometer measurements indicated that unity gradients existed when there was significant drainage, but gradients became less than unity as water drained away [Black and Spittlehouse, 1981]. Consequently, the $D(\theta)$ characteristic was approximated by the $k(\theta)$ characteristic for the root zone using $\theta$, though there was a slight overestimation of $D$ as $\theta$ decreased compared to the $D(\bar{\theta})$ characteristic. The $k(\theta)$ characteristic for the unsaturated range was $k=k_{r}(\theta / 0.3)^{(2 m+3)}$, with $m$ from the above mentioned retention characteristic [Campbell, 1974; Clapp and Hornberger, 1978] and $k_{r}=100$ mm $\mathrm{d}^{-1}$ from laboratory measurements of unsaturated conductivity on an undisturbed sample from the $0.3 \mathrm{~m}$ depth at site 2 [Spittlehouse, 1981]. This characteristic was also used for site 1 .

At site 1 in 1974 and site 2 in 1978, 24-hour net radiation was obtained $1 \mathrm{~m}$ above the canopy by electronically integrating the voltage output from a net radiometer. The value of the daily average air temperature $(\bar{T}) 1 \mathrm{~m}$ above the canopy was obtained by averaging 15-min readings in 1974 and by integration in 1978 of the voltage output of a ventilated diode temperature sensor. Rainfall and $\psi_{m}$ were measured daily and $\bar{\theta}$ was measured weekly with a neutron moisture probe. At site 2 in 1979 the daily maximum and minimum values of air temperature, $T_{\max }$ and $T_{\text {mun }}$, were obtained at $1.6 \mathrm{~m}$ above the forest floor with a hygrothermograph, and $\bar{T}$ was calculated as $\left(T_{\max }+T_{\operatorname{man}}\right) / 2$. Daily incident solar radiation $(K \downarrow)$ was obtained by integrating the voltage output from a pyranometer located $9 \mathrm{~km}$ from site 2. The value of $\bar{\theta}$ was obtained with a neutron moisture probe every 10 days, and the 10-day rainfall at site 2 was partitioned into daily totals on the basis of rainfall measurements at the site of the solar radiation measurements. Daily values of $\boldsymbol{R}_{n}$ were calculated from

$$
R_{n}=(1-a) K \downarrow+L^{*}
$$

where $a$ is the canopy reflection coefficient for solar radiation and $L^{*}$ is the daily net longwave radiation. The latter term was calculated from $L^{*}=\left(c+d K \downarrow / K \downarrow_{\max }\right)\left(\varepsilon_{a}-\varepsilon_{v}\right) \sigma \bar{T}^{4}$, where $K \downarrow_{\max }$ is the maximum possible, i. e., clear sky, $K \downarrow$ for the day, $c$ and $d$ are constants, $\sigma$ is the Stefan-Boltzmann constant, $T$ is in Kelvin, $\varepsilon_{a}$ is the apparent emissivity of the atmosphere, and $\varepsilon_{v}$ is the emissivity of the vegetation [Jury and Tanner, 1975]. Jarvis et al. [1976] suggest $\varepsilon_{a} \simeq 0.96$. Adjustment of $K \downarrow$ and $L^{*}$ to values for a nonhorizontal surface was not required, since the sites had slopes of $<10 \%$. Measurements in clear and cloudy conditions gave $a=0.12 \pm 0.02$ for site 1 in 1974 and site 2 in 1975 and 1978, in agreement with other values for coniferous forest [Jarvis et al., 1976]. Unlike the fraction of 


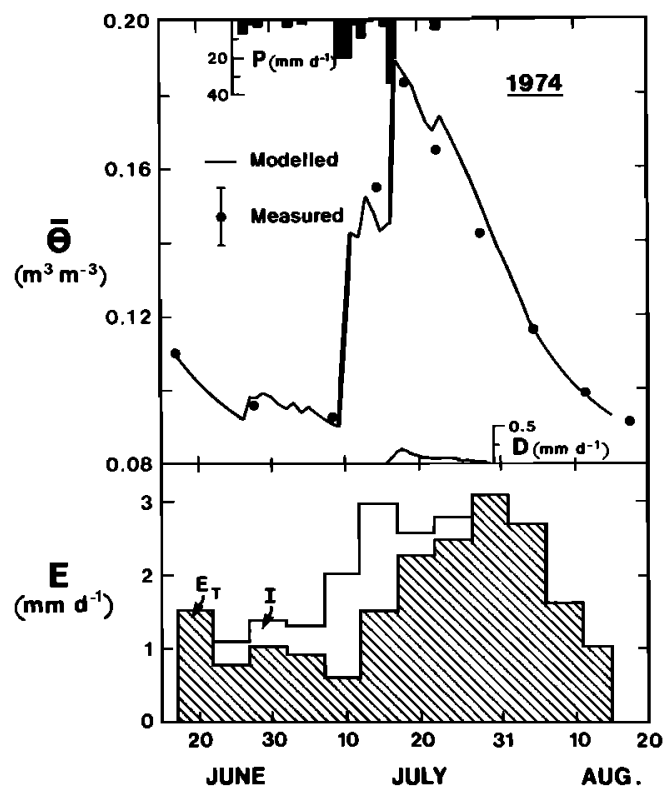

Fig. 2. Comparison of measured and modelled mean root zone water content $(\bar{\theta})$ for the site 1 Douglas fir stand in 1974. The bar indicates one standard deviation in the measured data. Also shown are modeled 5-day average daily drainage $(D)$, the transpiration $\left(E_{T}\right)$, and interception $(I)$ components of the modeled 5-day average daily evapotranspiration $(E)$, and the daily rainfall $(P)$.

daytime hours that have bright sunshine, which has a minimum value of zero, $K \downarrow / K \downarrow_{\max }$ has a minimum around 0.2 . Thus $c$ and $d$ were set equal to 0.1 and 0.9 , respectively, rather than the often-used values of 0.2 and 0.8 . This improved the estimation of low values of $\boldsymbol{R}_{n}$ and did not significantly affect the higher values. The value of $\varepsilon_{a}$ was calculated from $\bar{T}$ using the Idso-Jackson formula, $\varepsilon_{a}=1-(0.261 \exp (-7.77 \times$ $\left.10^{-4}(T-273)^{2}\right)$ ) [Aase and Idso, 1979]. Concurrent measurements of $K \downarrow$ and $R_{n}$ in 1975 and 1978 indicated that (6) consistently overestimated $R_{n}$ by about $15 \%$ when $K \downarrow / K \downarrow_{\max } \geq 0.5$, i. e., $R_{n} \geq 8 \mathrm{MJ} \mathrm{m}^{-2} \mathrm{~d}^{-1}$ during the summer. Reduction of $\varepsilon_{a}$ by $8 \%$ when $K \downarrow / K \downarrow_{\max } \geq 0.5$ corrected this systematic over-

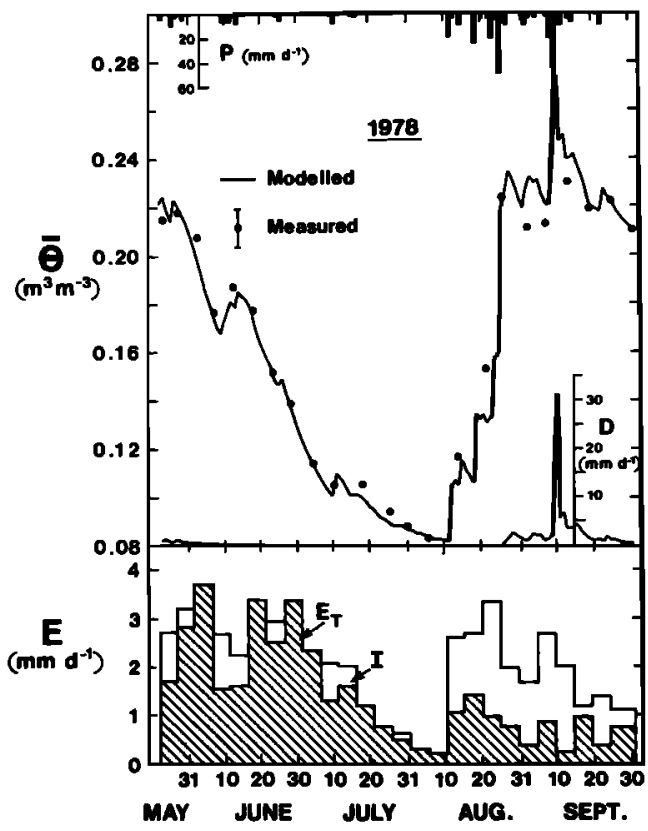

Fig. 3. As for Figure 2 but for site 2 in 1978.

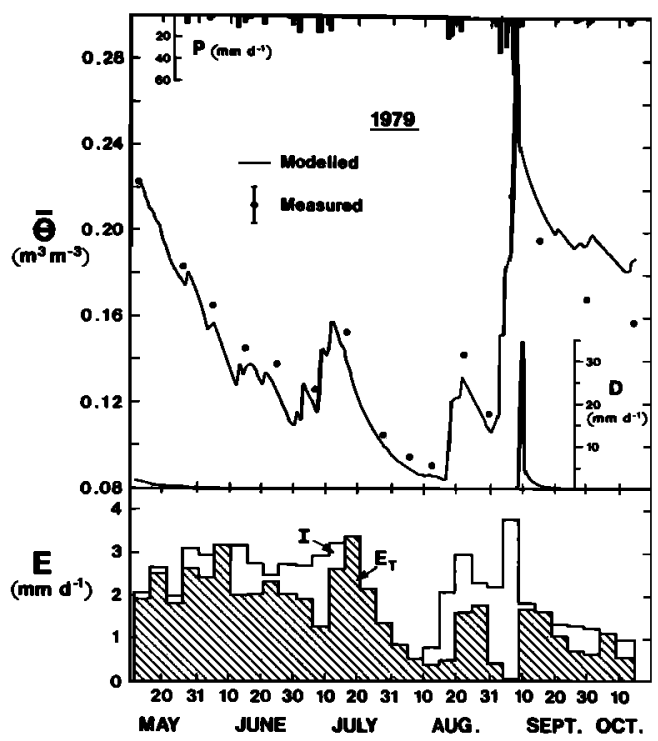

Fig. 4. As for Figure 2 but for site 2 in 1979.

estimation of $\boldsymbol{R}_{\boldsymbol{n}}$. A linear least-squares regression of modeled $\boldsymbol{R}_{n}$ (with corrected $\varepsilon_{a}$ ) on measured $\boldsymbol{R}_{n}$ had a correlation coefficient of 0.97 and $95 \%$ confidence limits $(n=169)$ of $\pm 1.8 \mathrm{MJ}$ $\mathrm{m}^{-2} \mathrm{~d}^{-1}$, i. e., $\pm 10 \%$ of the net radiation for a clear day in summer. Idso [1980] noted that formulae determined for clear skies in continental environments, e. g., the Idso-Jackson formula, overestimated $\varepsilon_{a}$ by about $7 \%$ in coastal environments.

\section{RESULTS}

The change in root zone water content was well simulated for site 1 in 1974 and site 2 in 1978 and 1979 (Figures 2-4, respectively). This was achieved for conditions when either drainage or evapotranspiration was the major term in the water balance. Consequently, this indicates that the submodels worked well independently of each other and the good simulation of $\bar{\theta}$ was not the result of compensating errors in the submodels. The model indicated that the interception of rainfall by the canopy significantly reduced the water available for transpiration. In 1974, 1978, and 1979, 19, 24, and 23\%, respectively, of the rainfall was intercepted for the periods modeled here. Similar values are reported for forest by Rutter [1975]. About 65\% of the intercepted rainfall can be consid-

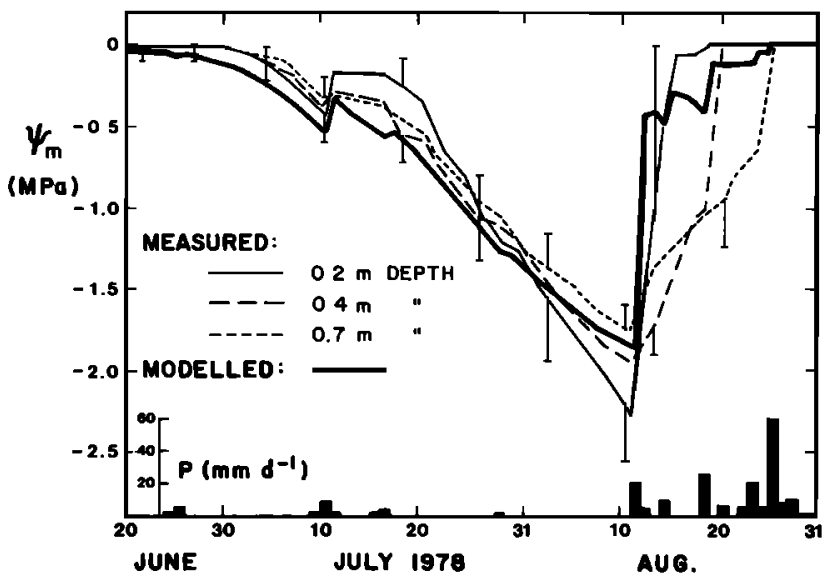

Fig. 5. Measured root zone matric potential $\left(\psi_{m}\right)$ at three depths, with bars (only one arm shown) indicating the range of the data, and modeled average $\psi_{m}$ of the root zone, for site 2 in 1978 . 
ered a net loss to the vegetation due to the fact that intercepted water evaporates at a greater rate than would transpired water. Additionally, for the periods modeled in 1978 and 1979,34 and $25 \%$ of the rainfall, respectively, was lost through drainage.

The Douglas fir trees were water-stressed for a significant period of time during the summer. For example, in 1978, $E_{T}<$ $E_{\max }$ for 41 days, resulting in an 84-mm water deficit for the stand. The simulated course of $\psi_{m}$ (Figure 5) indicated that the trees were severely stressed $\left(\bar{\psi}_{m}<-0.95 \mathrm{MPa}\right)$ for 21 days. There was good agreement with tensiometer and hygrometer measurements of $\psi_{m}$, especially considering the approximation involved in using an average matric potential characteristic for the $0.75-\mathrm{m}$-deep root zone. The severe stress was also confirmed by stomatal resistance and twig water potential measurements [Spittlehouse, 1981] and the observed severe browning of the needles in August 1978. In 1979, $E_{T}<E_{\max }$ for 39 days, resulting in a 58-mm deficit and 16 days when $\bar{\psi}_{m}<$ -0.95 MPa. Emmingham and Waring [1977] also found water stress induced stromatal closure in Douglas fir for significant periods during the summer in Oregon.

The usefulness of the model is enhanced if the modeled stand evapotranspiration $\left(E_{T}\right)$ can be partitioned between the trees and the understory or the forest floor. Plamondon [1972] found that the daily evapotranspiration from a moist Douglas fir forest floor with no understory was approximately equal to the water equivalent of daily $R_{n}$ at the forest floor minus the daily soil heat flux. Since forest floor $R_{n}$ at site 1 in 1974 was about $5 \%$ of that above the canopy, it can be inferred that forest floor evaporation had a minor effect on the soil water balance. Unpublished data of C. S. Tan and T. A. Black for site 2 in 1975 indicate that when soil water was not limiting transpiration, the daily transpiration from the salal understory, calculated using stomatal resistance, LAI, and vapor pressure deficit measurements [Tan et al., 1978], approximately equaled the $\boldsymbol{R}_{n}$ of the salal (about $25 \%$ of the above-canopy $\left.R_{n}\right)$. The appropriate value of $R_{n}$ can be estimated from the overstory LAI and an extinction coefficient $(\eta)$ for $R_{n}$ by multiplying the above-canopy $R_{n}$ by $\exp (-\eta \mathrm{LAI})$ [Jarvis et al., 1976]. Tan and Black's data suggest a value of 0.4 for $\eta$, which implies that salal $R_{n}$ was about $15 \%$ of the above-canopy $R_{n}$ at site 2 in 1978. The model indicated that $E_{T}$ was about $50 \%$ of above-canopy $R_{n}$ in the energy limited situation, which im-

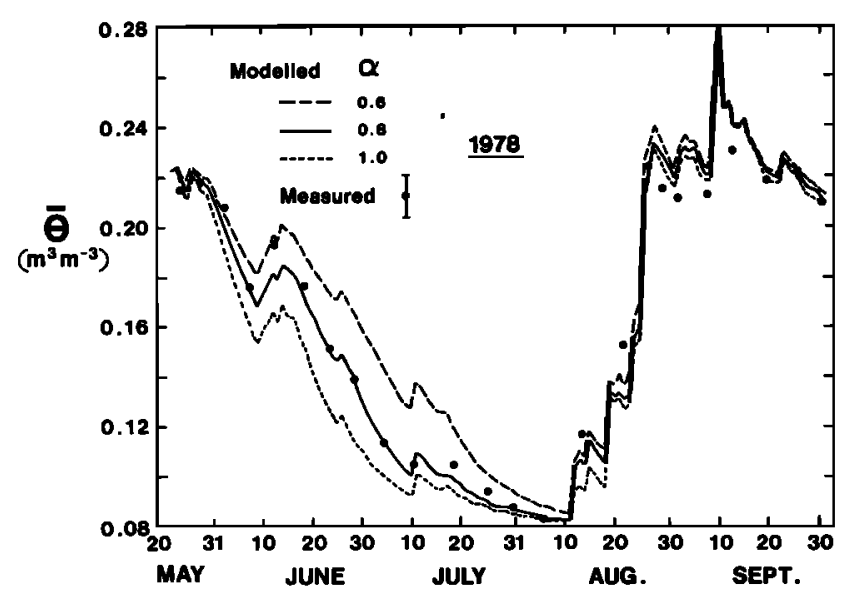

Fig. 6. Effect of a $25 \%$ change in $\alpha$ on the modeled average root zone water content $(\bar{\theta})$ for site 2 in 1978 . Measured $\bar{\theta}$ is also shown, with the bar indicating one standard deviation. plies that about $30 \%$ of $E_{T}$ was from the salal. Porometer measurements and a physiologically based evapotranspiration model [Spittlehouse, 1981, Spittlehouse and Black, 1981] indicate a similar partitioning of $E_{T}$. Partitioning between the trees and the understory when soil water is limiting can be accomplished if the ratio of their canopy resistances is known as a function of $\bar{\psi}_{m}$.

\section{Discussion AND CONCLUSIONS}

The negative feedback within the model from soil water content to evapotranspiration and drainage is partly responsible for the success of the model. Figure 6 illustrates that although a $25 \%$ change in $\alpha$ results in a small change in total water use for the growing season, the estimated stress duration is seriously in error. Further analysis suggests that an accuracy of $\pm 10 \%$ in $\alpha$ is required for reliable estimates of stress duration. The model is relatively insensitive to changes in $b$ and $g$ of up to $25 \%$. The calculation of drainage using the $k(\theta)$ characteristic evaluated at $\bar{\theta}$ appears to be adequate in freely draining, coarse soils.

McNaughton et al. [1979] and Shuttleworth and Calder [1979] warn against the indiscriminate use of (2) in evapotranspiration calculations. The discrepancy shown in Figure 4 between measured and modeled $\bar{\theta}$ in late September and early October 1979, is probably due to an underestimation of evapotranspiration by (2). The value of $\bar{\theta}$ during this period was such that soil water would not have been limiting evapotranspiration and drainage would have been negligible. Rainfall and the amount of water required to recharge trunk storage were minor terms in the water balance. The value of $E_{T}$ calculated using (1) with measured values of $P, I$, and $\bar{\theta}$ in October indicate $\alpha \simeq$ 1.1. Priestley and Taylor [1972] suggest that $\alpha$ is relatively constant over a wide range of air temperature. However, McNaughton et al. [1979], Jackson et al. [1976], and de Bruin and Keijman [1979] found $\alpha$ to increase from warm to cold seasons for pasture, bare soil, and a lake, respectively. The physiological response of the vegetation to the environment and mesoscale advective effects are incorporated in $\alpha$. Vegetation response characteristics and advective effects will vary between vegetation type and location and probably through the year; therefore, local determination of $\alpha$ is required. Our forest sites were located in extensive forested areas, and in this case $\alpha$ appears to be a reasonably conservative parameter for a major portion of the growing season. The unthinned and the recently thinned stands had the same values of $\alpha$ and $b$. These values were also suitable for the thinned site after a $20 \%$ increase in the total leaf area of trees and understory between 1975 and 1978 . Consequently, the canopy resistance characteristics of the thinned stand must have remained constant, which suggests either that the stomatal resistance characteristics of the vegetation must have changed or that the diffusive resistance within the canopy increased significantly [Spittlehouse and Black, 1981].

The coefficients of the model could be obtained from a carefully conducted water balance measurement program. Weekly measurements of $\bar{\theta}$, when $D$ is negligible and $P$ is zero, could be used to obtain weekly average values of $E_{T}$ from (1). The value of $\theta_{e}$ can be determined from $\bar{\theta}$, using the values of $\bar{\theta}_{\max }$ and $\bar{\theta}_{\min }$ at $\psi_{m}=-0.01 \mathrm{MPa}$ and $-2.5 \mathrm{MPa}$, respectively, in coarse soils. The average value of $E_{\text {eq }}$ can be calculated from measurements of $K \downarrow$ and $\bar{T}$. A plot similar to that in Figure 1 can then be obtained to give $\alpha$ and $b$. An in- 
terception function can be relatively easily determined, and laboratory or site measurements can be made to determine the $\bar{\psi}_{m}(\theta)$ and the $D(\bar{\theta})$ characteristics.

Acknowledgments. Funding was provided by grants from the Natural Sciences and Engineering Research Council of Canada, British Columbia Ministry of Forests, and the University of British Columbia. The research sites were provided by Crown Zellerbach, Courtenay Division. Mike Goldstein, Pat Wong, and the staff of the University of British Columbia's Oyster River Farm provided invaluable help during the field studies.

\section{REFERENCES}

Aase, J. K., and S. B. Idso, A comparison of two formula types for calculating long-wave radiation from the atmosphere, Water $R e$ sour. Res., 14, 623-625, 1978.

Black, T. A., Evapotranspiration from Douglas fir stands exposed to soil water deficits, Water Resour. Res., 15, 164-170, 1979.

Black, T. A., and D. L. Spittlehouse, Modelling the water balance for watershed management, in Interior West Watershed Management, edited by D. M. Baumgartner, pp. 117-129, Cooperative Extension, Washington State University, Pullman, Washington, 1981.

Black, T. A., W. R. Gardner, and G. W. Thurtell, The prediction of evaporation, drainage and water storage for a bare soil, Soil Sci. Soc. Am. Proc., 33, 655-660, 1969.

Campbell, G. S., A simple method for determining unsaturated conductivity from moisture retention data, Soil Sci., 117, 311-314, 1974.

Clapp, R. B., and G. M. Homberger, Empirical equations for some soil hydraulic properties, Water Resour. Res., 14, 601-604, 1978.

Clothier, B. E., D. R. Scotter, and J. P. Kerr, Drainage flux in permeable soil underlain by a coarse-textured layer, Soil Sci. Soc. Am. $J ., 41,671-676,1977$.

Cowan, I. R., Transport of water in the soil-plant-atmosphere system, J. Appl. Ecol., 2, 221-239, 1965.

de Bruin, H. A. R., and J. Q. Keijman, The Priestley-Taylor evaporation model applied to a large, shallow lake in the Netherlands. $J$. Appl. Meteorol., 18, 898-903, 1979.

Emmingham, W. H., and R. H. Waring, An index of photosynthesis for comparing forest sites in western Oregon, Can. J. For. Res., 7, 165-174, 1977.

Federer, C. A., A soil-plant-atmosphere model for transpiration and availability of soil water, Water Resour. Res., 15, 555-562, 1979.

Federer, C. A., and D. Lash, Simulated stream flow response to possible differences in transpiration among species of hardwood trees, Water Resour. Res., 14, 1089-1097, 1978.

Gash, J. H. C., Comments on the paper by A. S. Thom and H. R. Oliver, 'On Penman's equation for estimating regional evaporation,' Quart. J. R. Meteorol. Soc., 104, 532-533, 1978.

Harr, R. D., Water flux in soil and subsoil on a steep forested slope, $J$. Hydrol, 33, 37-58, 1977.

Hillel, D., and C. H. M. van Bavel, Simulation of profile water storage as related to soil hydraulic properties, Soil Sci. Soc. Am. J., 40, 807815,1976 .

Idso, S. B., On the apparent incompatibility of different atmospheric thermal radiation data sets, Quart. J. R. Meteorol. Soc., 106, 375$376,1980$.

Item, $H$., A model for the water regime of coniferous forest and grassland, J. Hydrol., 37, 323-332, 1978.

Jackson, R. D., S. B. Idso, and R. J. Reginato, Calculation of evaporation rates during the transition from energy-limiting to soil-limiting phases using albedo data, Woter Resour. Res., 12, 23-26, 1976.
Jarvis, P. G., G. B. James, and J. J. Landsberg, Coniferous forest, in Vegetation and the Atmosphere, vol. 2, Case Studies, edited by J. L. Monteith, pp. 171-240, Academic, New York, 1976.

Jury, W. A., and C. B. Tanner, Advection modification of the Priestley and Taylor evapotranspiration formula, Agron. J., 67, 840-842, 1975.

McNaughton, K. G., Evaporation and advection I: Evaporation from extensive homogeneous surfaces, Quart. J. R. Meteorol. Soc., 102, 181-191, 1976.

McNaughton, K. G., and T. A. Black, A study of evapotranspiration from a Douglas fir forest using the energy balance approach, Water Resour. Res., 9, 1579-1590, 1973.

McNaughton, K. G., B. E. Clothier, and J. P. Kerr, Evaporation from land surfaces, in Physical Hydrology: New Zealand Experience, edited by D. L. Murray and P. Ackroyd, pp. 97-119, New Zealand Hydrological Society, Wellington North, New Zealand, 1979.

Monteith, J. L., Principles of Environmental Physics, Edward Arnold, London, 1973.

Nnyamah, J. U., and T. A. Black, Rates and patterns of water uptake in a Douglas-fir forest, Soil Sci. Soc. Am. J., 41, 972-979, 1977.

Plamondon, A. P., Hydrologic properties and water balance of the forest floor of a Canadian west coast watershed, Ph.D. thesis, Univ. of British Columbia, Vancouver, B.C., 1972.

Priestley, C. H. B., and R. J. Taylor, On the assessment of surface heat flux and evaporation using large-scale parameters, Mon. Weather Rev., 100, 81-92, 1972.

Rutter, A. J., The hydrological cycle in.vegetation, in Vegetation and the Atmosphere, vol. 1, Principles, edited by J. L. Monteith, pp. 111154, Academic, New York, 1975.

Sharma, M. L., and R. J. Luxmoore, Soil spatial variability and its consequences on simulated water balance, Water Resour. Res., 15, 1567-1573, 1979.

Shuttleworth, W. J., and I. R. Calder, Has the Priestley-Taylor equation any relevance to forest evaporation? J. Appl. Meteorol., 18, 639-646, 1979.

Spittlehouse, D. L., Measuring and modelling evapotranspiration from Douglas-fir stands, Ph.D. thesis, Univ. of British Columbia, Vancouver, B. C., 1981.

Spittlehouse, D. L., and T. A. Black, Evaluation of the Bowen ratio/ energy balance method of determining forest evapotranspiration, Atmosphere-Ocean, 18, 98-116, 1980.

Spittlehouse, D. L., and T. A. Black, Measuring and modelling forest evapotranspiration, Can. J. Chem. Eng., 59, 173-180, 1981.

Stewart, J. B., Evaporation from the wet canopy of a pine forest, $\mathrm{Wa}$ ter Resour. Res., 13, 915-921, 1977.

Tan, C. S., T. A. Black, and J. U. Nnyamah, A simple diffusion model of transpiration applied to a thinned Douglas-fir stand, Ecology, 59, 1221-1229, 1978.

Thornthwaite, C. W., J. R. Mather, and D. B. Carter, Instructions and tables for computing potential evapotranspiration and the water balance, Publ. Climatol. 10(3), Drexel Inst. Technol., Lab. Climatol., Centerton, N. J., 1957.

van Wijk, W. R., and D. A. de Vries, Evapotranspiration. Neth. J. Agric. Sci., 2, 105-119, 1954.

Zahner, R., Refinement in empirical functions for realistic soil-moisture regimes under forest cover, in International Symposium on Forest Hydrology, edited by W. E. Sopper and H. W. Lull, pp. 261-274, Pergamon, New York, 1967.

(Received March 10, 1981; revised June 29, 1981; accepted July 16, 1981.) 